\title{
THE BUILT ENVIRONMENT OF FARM WINERIES: AN ANALYSIS METHODOLOGY FOR DEFINING META-DESIGN REQUIREMENTS
}

\author{
Patrizia Tassinari, Sergio Galassi, Stefano Benni, Daniele Torreggiani
}

\section{Introduction}

The study represents the first step of a broader research aimed at defining specific building and landscape design criteria for small to medium-sized wine farms, to which the most common standards of industrial wineries cannot be applied. The scientific literature includes several specific studies about the design of industrial wineries [Ayuga 1999; Bailey 2002] and technical and functional features of equipment and facilities necessary for the production process [Jacquet 2007; Fuller 2004], whilst no systematic framework of design references for farm wineries is available.

Methodological frameworks regarding the broader theme of building design for agroindustrial facilities have been proposed by several authors [Fichera 1995], who recognized the meta-design as a crucial phase for the definition of a correct decision process [van der Voordt 2005]. Meta-design allows to achieve a virtuous interaction between choices regarding building aspects and needs of the transformation process, as it properly links production functional requirements and built spaces performances.

With reference to the above-mentioned farm typologies and the wine-growing and producing sector of the Emilia-Romagna region (Italy), the study aims at identifying the main knowledge references for the formulation of meta-design requirements. In particular, this goal is organized into the following specific objectives:

- identification of a significant study area, as for both potential and actual production;

- analysis of the wine-growing and producing sector in the study area and the main production features of the farms under study;

Paper received 30.08.2010; accepted 16.12.2010

PATRIZIA TASSINARI, full professor; STEFANO BENNI, researcher; DANIELE TORREGGIANI, researcher; Dept. of Agricultural Economics and Engineering, Spatial engineering division, University of Bologna, Viale G. Fanin, 48 - 40127 Bologna, Italy. E-mail patrizia.tassinari@unibo.it Tel. +39 051 2096170. SERgio Galassi, full professor; Dept. of Food Science University of Bologna, Piazza Goidanich 60-47023 Cesena Italy
- formulation of a preliminary framework of the main building code provisions for the spatial units of wineries.

\section{Materials and methods}

First the research focused on the identification of a study area representative in terms of wine-growing and wine production within the considered regional context. Processing the most recent production data available referred to 2007 [Emilia-Romagna Region 2008] allowed us to identify a representative provincial territory on the basis of the least overall deviation of the main production parameters (vineyard area, quantities of produced grape and wine) from average regional values.

Then, in the considered province, we analysed vineyard sizes based on data surveyed in each municipality for the most recent census of agriculture [Istat 2000], thus identifying a super-municipal area which proved representative as for the ratio of vineyard area to total land area, indicative of the wine-growing attitude. A GIS analysis allowed us to perform a geo-morphological characterization of vineyard parcels, derived from the "vineyard cadastre" vector geodatabase provided by the competent bureau of the provincial government.

We studied in depth the features of the wine-growing and producing sector through the analysis of the available data collected by the institutions in charge of licences, verifications and inspections of the agrofood processing activities and wine producers' associations. In particular the local Department of Public Health (AUSL) provided us with the database of all the wineries authorized or registered under the Law by Decree 193/07 [Italian Republic 2007]. Processing such a database allowed us to characterize the sector in terms of distribution of annual production capacities and thus to identify the most frequent production classes in the study area, in order to focus on these the subsequent analyses of the production process.

Such analyses called for the creation of a highly detailed database founded upon specific parameters, to be surveyed on a representative sample of farms 
and processed on the basis of an inferential approach. To this end, within the identified classes of production size, we selected a sample of farms whose frequency distribution of wine production quantities basically reproduced the whole population's one, checking the availability of necessary information. This selection was supported by the Regional Prevention Environment Agency (ARPA) and farmers associations. In particular ARPA provided data concerning winegrowing (vineyard size, quantities of grapes produced, acquired, sold) and wine production (quantities of grapes processed and wine produced, divided into the main categories, and the kind of commercialisation, loose or bottled), quantities of drawn and waste waters, waste management systems, and presence of agritourism. Then we prepared a specific questionnaire and administered it to farmers, with the support of farmers associations, to get further information about vine cultivars, tank capacities and main marketing strategies. Sampled data were organized into a geodatabase and integrated with those derived from vineyard maps and cadastral data. Finally we analysed the local technical regulations for winery design in order to identify a framework of the main building requirements and work out a table of the corresponding indicative parameters. The analysis was performed with the collaboration of the Public Health Department and the Municipal technical services of the study area, and involved the compared analysis of Decree 380/2001, Laws by Decree 152/2006, 193/2007, 4/2008, 81/2008 [Italian Republic 2001, 2006, 2007, 2008a, 2008b], as well as the municipal building and hygiene codes.

\section{Results and discussion}

\subsection{Definition of a study area}

Grape production in Emilia-Romagna in 2007 was 738,714 tons, and involved 56, 496 ha of vineyards. In the same year the regional wine production was $5757 \times 10^{6} \mathrm{hl}, 34 \%$ of which being table wine, $40 \%$ IGT (Typical Geographic Indication), and $26 \%$
VQPRD (Quality Wines Produced in Certain Regions, i.e. Controlled Denomination of Origin, DOC, and Controlled and Guaranteed Denomination of Origin, DOCG). Data about production and surface area referred to each province of the considered region are broadly diversified (Fig. 1), being those of the Bologna province the closest to the regional average: differences are $+11 \%$ for vineyard surface areas, $+16 \%$ for grape production, $-3 \%$ for wine production; whilst product division into table wines and brand products matches regional rates. The analyses have shown that, in this province, $55 \%$ of vineyards surface area and $95 \%$ of IGT and $75 \%$ of DOC wine production are concentrated in the New District of Imola (NCI), a super-municipal $787 \mathrm{~km}^{2}$ area covering $21 \%$ of the province, thus chosen as the study area. It represents an association of municipalities, to which certain provincial and regional administrative functions are delegated, that is currently formulating its intermunicipal land-use plan (defined Structural Plan by Regional Law 20/2000, [Emilia-Romagna Region 2000]) and the relative town planning and building code. Since the authors are members of the workgroup supporting this process, this study also contributes to a broader work aimed at the knowledge of the features of the various agricultural sectors, including food processing, functional to the development of the above planning and technical regulation tools.

\subsection{Characters of the wine-growing and producing sector in the study area}

The study area shows heterogeneous geo-morphological characters, which may be synthetically represented (Fig. 2) through the identification of suitable altimetry classes and land suitability classes for agricultural and forestry use (hereafter shortened to land suitability). We have defined three altitude thresholds [Tassinari 2007] corresponding to $50 \mathrm{~m}, 300 \mathrm{~m}, 600$ $\mathrm{m}$ above sea level. They subdivide the territory respectively into fully plain areas (below $50 \mathrm{~m}$, representing the $46 \%$ of the study area), hill-foot areas (between $50 \mathrm{~m}$ and $300 \mathrm{~m} ; 38 \%$ ), fully hilly areas (between $300 \mathrm{~m}$ and $600 \mathrm{~m} ; 15 \%$ ) and piedmont areas
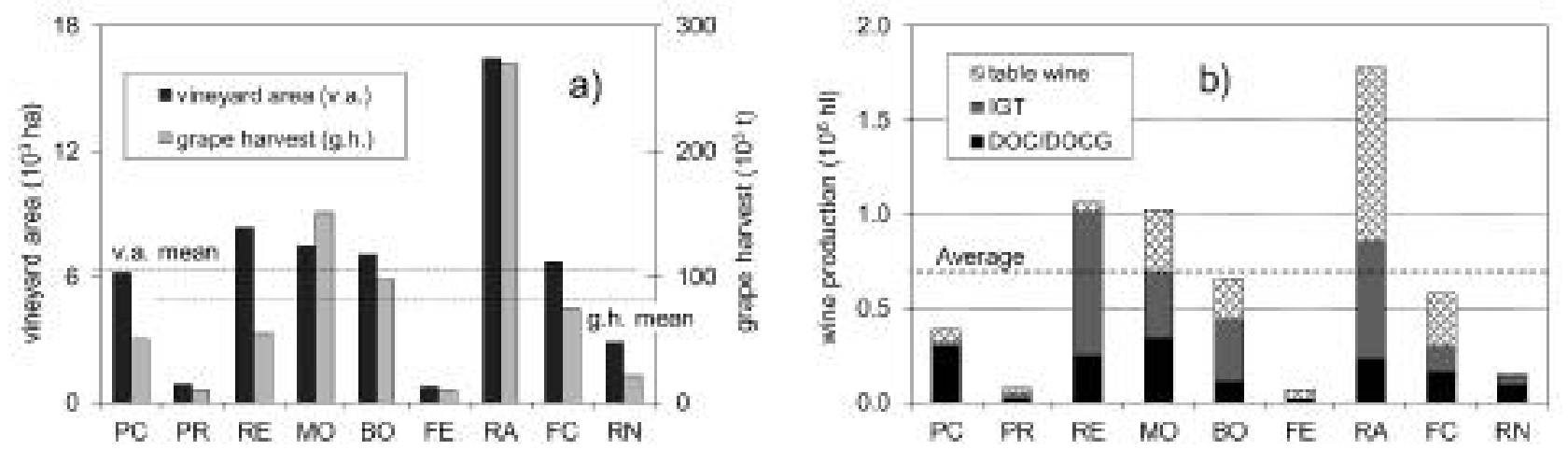

Fig. 1 - Vineyard surface areas and quantities of grapes harvested (a) and wine production (b) in the various provinces of the Emilia-Romagna region in 2007. 


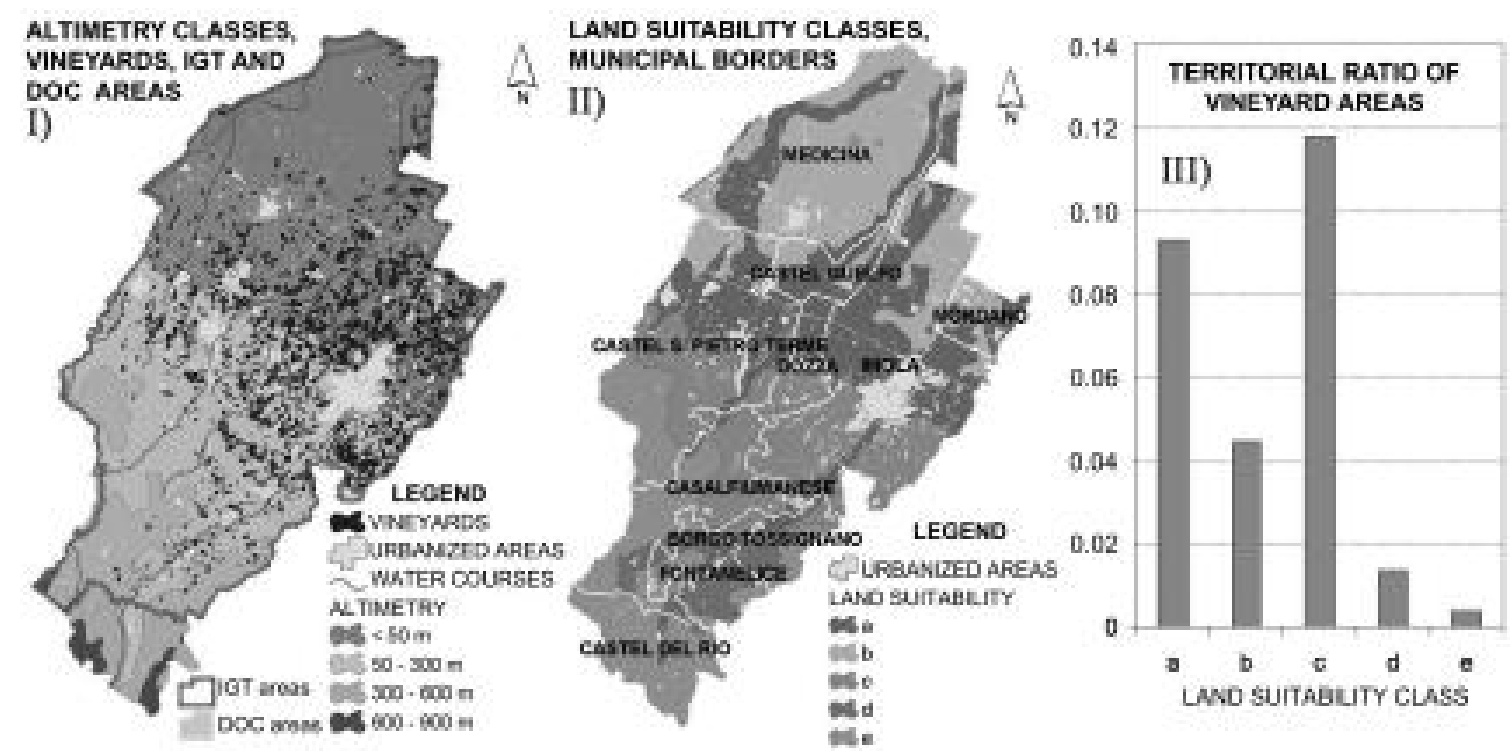

Fig. 2 - Characterization of the study area: I) vineyards distribution and altimetry classes; II) municipalities and land suitability classes; III) vineyard areas incidences in the various land suitability classes.

(above $600 \mathrm{~m} ; 1 \%$ ). The land suitability classes, defined on the basis of a combined analysis of land capability, elevation and morphology, are:

a) level land well suited for agricultural use $(32 \%$ of the study area);

b) level land less suited for agricultural use than class a areas $(24 \%)$;

c) hill-foot and hilly regions with an intermediate suitability for agricultural use (22\%);

d) hilly regions moderately suitable for agricultural use (4\%);

e) areas with low suitability for agricultural use $(18 \%)$.

Analyses of cultivated land performed in the GIS environment (Fig. 2-I) have pointed out that $46 \%$ of vineyards are located in plain land and the remaining ones in hill foot areas, and that almost all vineyard parcels are within IGT production districts, and 95\% within DOC districts too. On the basis of the land suitability classification (Fig. 2-II, III), $c$ class lands show the overall highest incidence of vineyards surface area (corresponding to $38 \%$ of total vineyards), whilst $44 \%$ of vineyards of the study area are located in $a$ class lands and only $16 \%$ in $b$ class ones. These data highlight that vineyard locations greatly depend on land suitability, and that a territorial analysis solely based on altimetry classes is not enough to identify the landscapes mostly characterized by viticulture.

The analysis of wine production data allowed to identify 146 wineries, whose production capacities vary from $14 \mathrm{hl}$ to $290000 \mathrm{hl}$ per year, and in most cases $(90 \%)$ do not exceed 5000 hl per year. Consistently with the study aims, we focused on these wineries, which are likely to be farms mainly processing their own grapes.

The data analyzed have been represented in the histogram of Figure 3, where each rectangle is erected over a production interval with an area equal to the relative frequency of the observations. Such a diagram clearly shows that year production of most farm wineries $(76 \%)$ is under $1000 \mathrm{hl}$, exceeding $2500 \mathrm{hl}$ in few cases $(4 \%)$.

According to the procedures described in section 2, we selected a sample of 46 farm wineries within those whose annual production did not exceed $5000 \mathrm{hl}$ (Fig. 4.a), corresponding to a $35 \%$ sampling ratio. With reference to the above-mentioned altimetry classes, $2 / 3$ of the sampled farms are located in hill-foot areas and cover $2 / 3$ of the total wine production of the sample, whilst the remaining farms are located in plain areas. As regards land suitability classes, $60 \%$ of wine is produced by wineries located in $c$ class areas, $39 \%$ by those located in $a$ class, and remaining $1 \%$ in $e$ class areas.

Average size of wine farms in terms of total farmland is 30 ha, whereas the mean vineyard area is 15 ha. Frequency distribution of wine farms in function of their overall size appears quite irregular, whilst

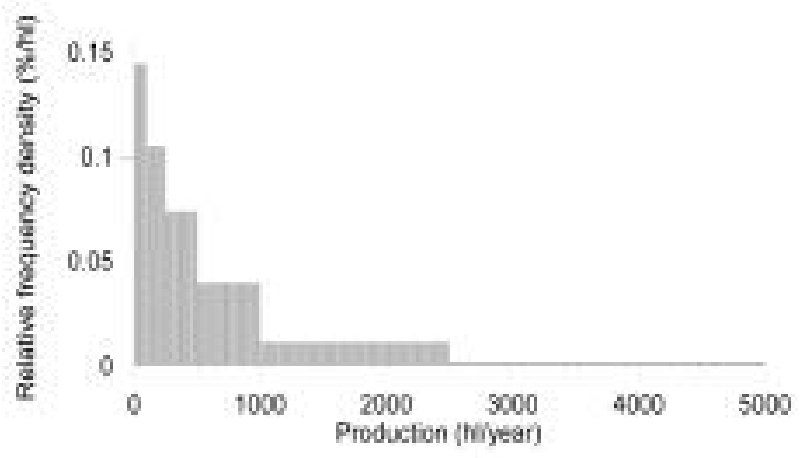

Fig. 3 - Histogram of yearly wine production quantities for the wineries in the study area. 
their frequency distribution in function of vineyard surface areas shows a clear peak corresponding to 510 ha and 10-20 ha classes (Fig. 4.b), which together represent $54 \%$ of farms, their separating value (10 ha) also being the median of the distribution. Farm distributions based on quantities of produced and processed grape are reported in Figure 4.c. Average annual quantities of grapes produced and processed amount to 165.2 tons and 189.6 tons respectively. Therefore these farms acquire on an average $15 \%$ of processed grape by other farms. We also investigated grape harvesting modalities, given their well known implications in the wine-making process. It resulted that almost half of the farms $(46 \%)$ uses only manual harvesting; in all other cases mechanized and manual harvesting are adopted jointly.

The farms under study grow manifold cultivars: Trebbiano romagnolo (45\% of total vineyard areas), Sangiovese (19\%) Albana (10\%), Pignoletto (8\%), Cabernet Sauvignon (4\%), Chardonnay (4\%), Malvasia Bianca di Candia (4\%), Merlot (2\%), Barbera (1\%), Uva Longanesi (1\%), Pinot bianco (1\%), and others $(1 \%)$. Such variety reveals the trend of farms towards profiting from niche markets. The allocation of produced wines into the above-mentioned categories reflects the regional one, as a further confirmation of the sample representativeness. As for the winemaking process, all the sampled farms produce both white and red wines. White wines represent $60 \%$ of the whole production (25\% table wine, $23 \%$ IGT, and $12 \%$ VQPRD) and red wines the remaining part (9\% table wines, $16 \%$ IGT and 15\% VQPRD). The mean overall capacity of wine tanks of each farm is $1800 \mathrm{hl}$ and the values distribution (Fig. 5.a) shows that in $69 \%$ of wineries overall capacity is not greater than $2000 \mathrm{hl}$.

The average quantity of drawn water, essentially used for washing winery spaces, tanks, equipments, and bottles, results equal to $155 \mathrm{~m}^{3} /$ year (Fig. 5.b). No clear correlation is recognizable between production quantities and volumes of used water (ratios of used water to produced wine volumes vary from 0.2 to 4.5 , 1.3 on an average), as the latter strongly depends on the size of bottling activities, which require great water volumes in case non sterile bottles are used.

Nevertheless, data about wastewater volumes for the sampled wineries, besides being comparable to drawn water volumes, proved fundamentally consistent with those reported in scientific literature [Farolfi 1995; Berta 2003]. Wastewaters of the considered wineries are classified according to national law in force (Legislative Decree 152/2006 [Italian Republic 2006]) as industrial assimilated to domestic, as far as they produce at least $2 / 3$ of processed grapes. According to the provisions of Deliberation $1053 / 2003$ by the Regional Government [Emilia-Romagna Region 2003], the treatment system generally adopted consists in an oil-water separator, an Imhoff tank, and one of the following systems: a rotating biological contactor, a trickling filter, a total oxidation plant, or a phytodepuration system. ARPA generally suggests the adoption of an Imhoff tank and a sub-irrigation system when wastewater volumes do not exceed 10 equivalent inhabitants.

Only $15 \%$ of farms, with $2700 \mathrm{hl}$ average annual production, bottle their wine on their own; wineries
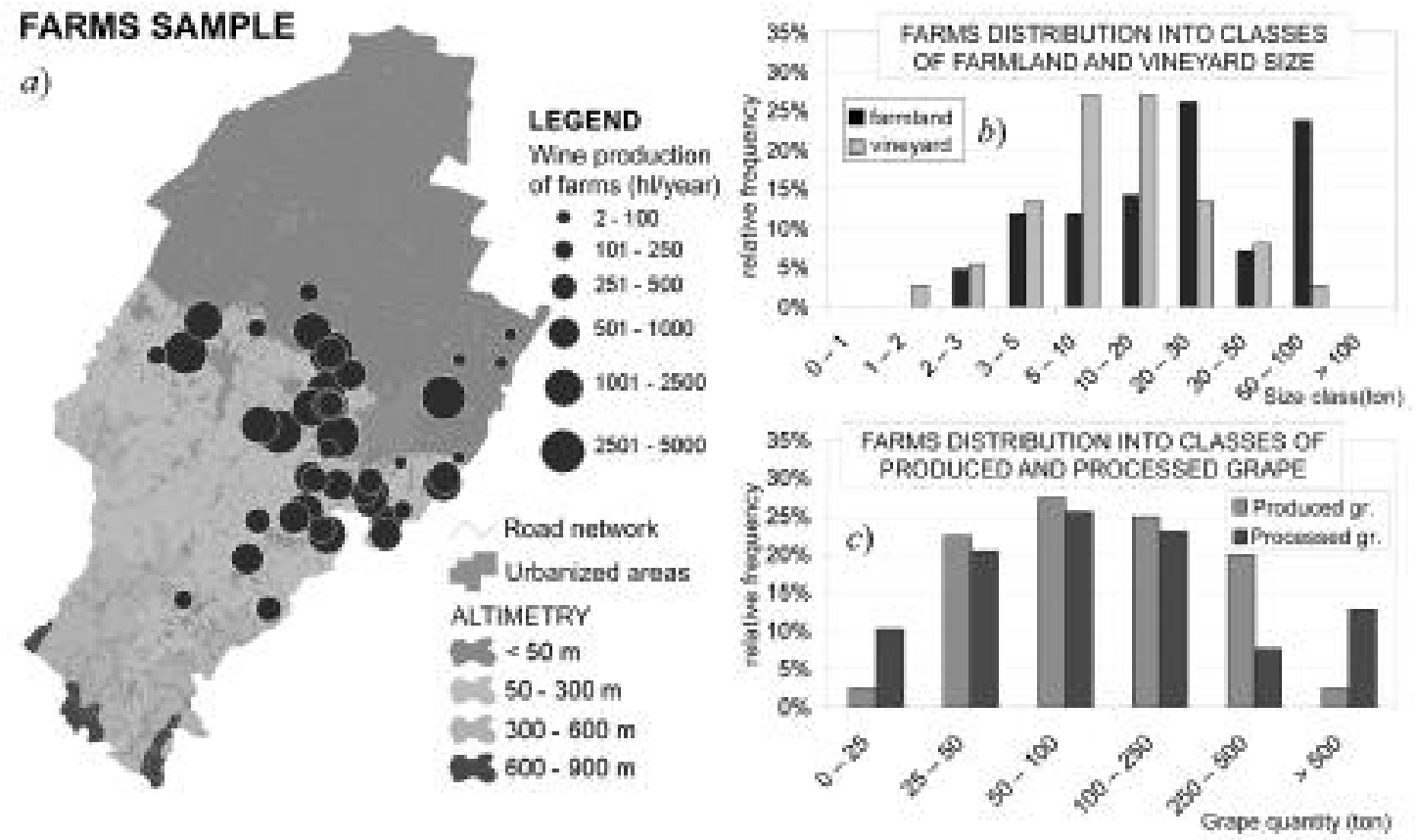

Fig. 4 - a) Location of the sampled farms and their wine production. b) Distribution of the sampled farms based on overall size and vineyard size classes, according to intervals defined by the Italian Statistic Board [Istat 2000]. c) Distribution of the sampled farms based on quantities of grape produced and processed. 

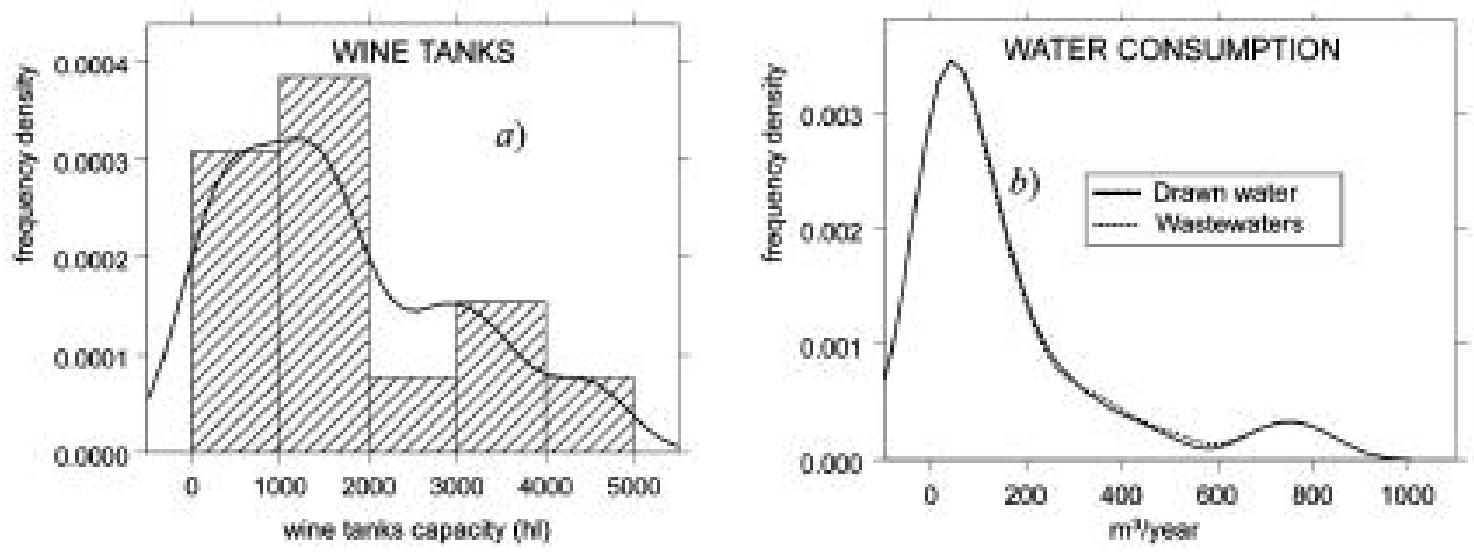

Fig. 5 - a) Histogram and equalized histogram of wine tanks capacity of the sampled wineries. b) Equalized histograms of the volumes of drawn water and wastewaters of the wineries.

with no bottling equipment have a definitely smaller production size (860 $\mathrm{hl} /$ year on an average). All the sampled farms provide tasting services and direct selling, and have a visitor car parking area for this purpose.

Farms providing also agritourism service are $13 \%$ and have a mean vineyard area and an average wine production of $10 \mathrm{ha}$ and $670 \mathrm{hl} /$ year respectively, therefore remarkably smaller than those of the remaining farms, which are 14 ha and $1200 \mathrm{hl} /$ year respectively. Conversely, agritourism farm wineries are characterized by a greater average overall farm size ( 38 ha vs. 29 ha). The marketing trends of these farms appear therefore more broadly diversified, also outside the wine sector.

\subsection{Building requirements for farm wineries}

The analyses referred to building technical regulations, developed as described in section 2, have led to the identification of the main spatial units that, according to code provisions currently in force, have to be included when planning the spatial layout of a winery, both in the design of new buildings and transfor- mation of existing ones. Such units are summarized in the scheme of Figure 6 and are referred to according to the numeration reported in the scheme itself.

In case grapes are not poured directly inside the winery, an outdoor sheltered drivable space is required for the grape receipt area (1). Within the building, proper development of the wine-making process and the disposition of the necessary equipments call for at least one room (2) to be planned, organized into two distinct sectors, dedicated to must production and the arrangement of wine tanks respectively. A further room (3) is required to contain the oenological products (additives and technological adjuvants); an alternative is to use a washable and disinfectable properlysized cabinet. Moreover at least one toilet (4) for the workers has to be planned, including one washbasin every ten workers and an access area, a changing room (5), and a shower room (6), with a shower every ten workers. In wineries producing bottled wine, in case bottling activities are not performed using temporary equipments, a dedicated room or suitable area of the wine-making room has to be planned for bottling and packaging (7), equipped with at least one

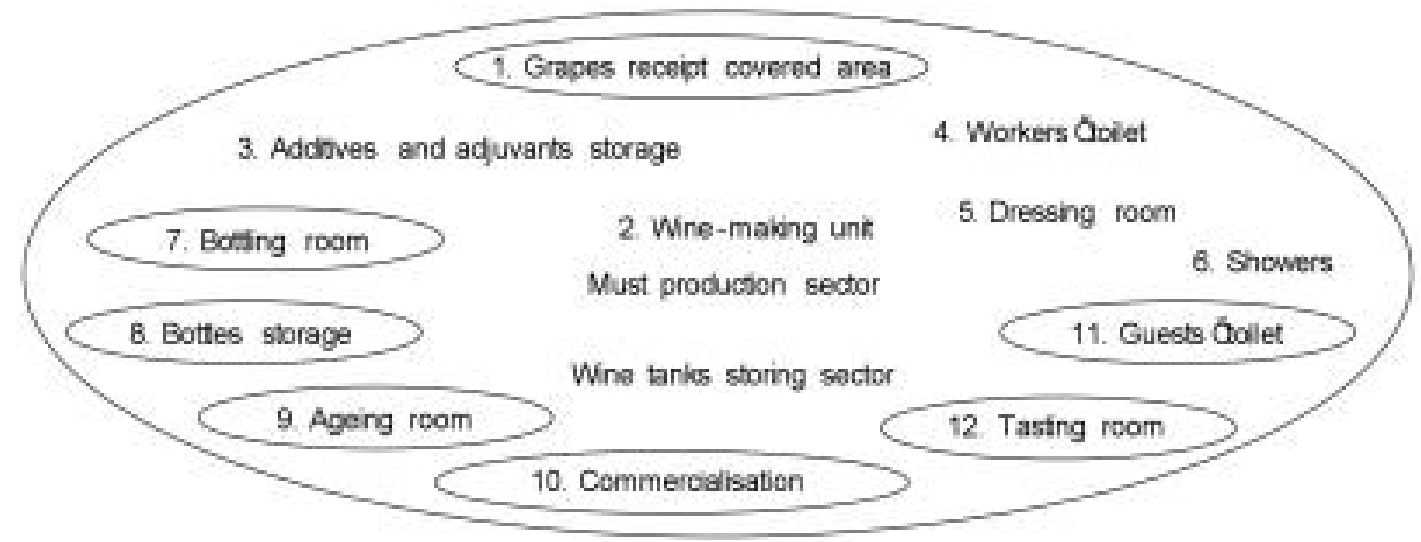

Fig. 6 - Conceptual scheme of the spatial units of a winery. Broken contour lines indicates rooms that may not be present, depending on process features and marketing choices. 


\begin{tabular}{|c|c|c|}
\hline & SU & REQUIREMENTS AND PARAMETERS \\
\hline \multirow{4}{*}{$\mathbf{H}$} & 2 & $3 \mathrm{~m}$ \\
\hline & $3,8,9$ & $2.40 \mathrm{~m} ; 2,70 \mathrm{~m}$ if any work position is hosted \\
\hline & $5 ; 6 ; 10$ & $2.70 \mathrm{~m}$ \\
\hline & $4 ; 11$ & $2.40 \mathrm{~m}$ \\
\hline \multirow{2}{*}{$\mathbf{S}$} & 4 & $1.2 \mathrm{~m}^{2}$ per WC \\
\hline & 5 & $1.2 \mathrm{~m}^{2} /$ worker; $\geq 2 \mathrm{~m}^{2}$ \\
\hline \multirow{3}{*}{$\mathbf{L}$} & $2,5,7,10,12$ & $1 / 8$ \\
\hline & $3,8,9$ & $1 / 8$; not required in rooms only occasionally used \\
\hline & 4,11 & $1 / 8 ; \geq 0.60 \mathrm{~m}^{2}$ \\
\hline \multirow{3}{*}{$\mathbf{V}$} & $2,5,7,10,12$ & $1 / 16$ \\
\hline & $3,8,9$ & $1 / 16$; not required in rooms only occasionally used \\
\hline & 4,11 & $1 / 16 ; \geq 0.60 \mathrm{~m}^{2}$ \\
\hline \multirow{3}{*}{$\mathbf{P}$} & 1 & drivable concrete paving \\
\hline & $2,7,8$ & washable paving with draining system \\
\hline & $4,5,6,11$ & tiled floor \\
\hline \multirow[t]{2}{*}{$\mathbf{W}$} & $2,7,8$ & $\begin{array}{l}\text { tiling or plaster with washable anti-mould painting. For stone facing } \\
\text { walls: painting with transparent washable anti-dust resins. At least up } \\
\text { to tanks height or storing height, however } \geq 2 \mathrm{~m}\end{array}$ \\
\hline & $4,5,6,11$ & full height walls, tiling at least up to $2 \mathrm{~m}$ \\
\hline
\end{tabular}

TABLE 1 - Main requirements and relative indicative parameters for the spatial units (SU) of wineries, in terms of minimum height $(\mathrm{H})$, minimum surface area $(\mathrm{S})$, minimum ratio of natural lighting surface area to room area $(\mathrm{L})$, minimum ratio of natural ventilation surface area to room area $(\mathrm{V})$, paving features $(\mathrm{P})$ and wall requirements $(\mathrm{W})$.

sink. If direct selling to the public is provided, a suitable room or area for commercialisation (10) is required. For tasting activities it is necessary that the winery includes a toilet for guests (11), accessible for disabled persons, and a tasting room (12).

We have performed a detailed synthesis of building requirements provided for wineries and relative design parameters, reported in Table 1 . These parameters are meant as quali-quantitative indications of minimum reference standards, to be compared and integrated with the provisions of building and hygiene codes in force in each municipality.

In many existing wineries located in old rural buildings, the above parameters often result inapplicable, due to structural constraints. Although meeting the described requirements would assure the best functionality and safety conditions, the trend shared by technical officers of the various public institutions of the study area is to allow specific derogations for family-run farm wineries which do not perform bottling operations. In particular, in those cases it is provided that workers may use the toilet and the bathroom of farmers' homes, the minimum height for all the spatial units is $2.40 \mathrm{~m}$, and minimum natural lighting and ventilation ratios are not considered as compulsory.

\section{Conclusions}

The study has led to the identification of the main basic elements useful for the definition of meta-de- sign requirements for small to medium-sized farm wineries, with reference to a study area in the EmiliaRomagna region (Italy). The results allowed to outline a preliminary framework of design references, related both to the main quali-quantitative characteristics of the production processes typical of the case study, and current law requirements of the considered sector.

In particular, the results regarding the sizes of the wine-growing and producing activities, the categories of wine produced and the modalities of bottling and packaging, and product presentation and commercialisation have pointed out the distinctive features of the considered farm typologies, for which few outcomes of specific studies were available. Moreover, the results of integrated analyses of code provisions and indications of the various regulation fields involved in the design process have led to define the main spatial units of wineries and the respective functional requirements and dimensional parameters. These have a fundamental importance to translate the functional needs of the investigated production processes into preliminary design solutions.

This study is part of a research project aimed at the combined reading of the above results and further outcomes of on-site surveys on a sample of wine farms, that will be the subject of future work, in order to analyse performance requirements of existing wineries. Based on the results of such analyses, we aim to identify the main design issues of the sector, and define a framework of proper technical and architectonic solutions. 


\section{Acknowledgments}

We thank for the data made available and the precious collaboration the New District of Imola (NCI), the Department of Public Health (AUSL) of Imola, the Regional Prevention Environment Agency (ARPA) of Imola, the Corporation for Protection of Romagna Wines. The study has been performed within the research project PRIN 2007 "New building design methodologies for wine-growing farms", funded by the Italian Ministry of Education, University and Research (MIUR).

\section{References}

Ayuga F. Wine Processing. In: CIGR Handbook of Agricultural Engineering. Volume IV Agro-Processing Engineering. Ed Bakker-Arkema F.W. ASAE, St. Joseph, Michigan, 1999, pp. 419-446.

Bailey R., Parish M., Baldwin G. Winery Design in the 21st Century. Australia \& New Zealand Wine Industry Journal, 2002, 17(6), 40-44.

Berta P., Minetti M., Stecchi, R. Il trattamento delle acque reflue in enologia. (Wine-making wastewater management). Tecniche nuove, Milano, Italy, 2003.

Emilia-Romagna Region. Law 6 June 2009, nr. 6. Governo e riqualificazione solidale del territorio. (Land government and loyal requalification). Regional Official Gazzette 116, 2009, Bologna, Italy.

Emilia-Romagna Region. Govenrment deliberation nr. 1053 of 9 June 2003. Regional Official Gazzette 63, 2003, Bologna, Italy.

Emilia-Romagna Region. Produzione lorda vendibile 2007. (Marketable gross production 2007). Ed. Assessorato Agricoltura, Servizio Programmi, Monitoraggio e Valutazione, Bologna, Italy, 2008.

Farolfi S. La gestione dei reflui enologici sul territorio. Avenue Media, 1995, Bologna, Italy.

Fichera C.R., Tomaselli G., Di Fazio S. La metaprogettazione edilizia per l'industria agraria. Note di metodo. (Meta-design in agricultural industry. Method notes). In: Rivista di Ingegneria Agraria. Quaderno n. 18. Ed. Amirante P., Failla A., Bruno C., Marzano F., AIIA, Bari, 1995, pp. 45-58.

Fuller R.J., Luther M.B., Cheung C.K. Performance of a commercial wine store with insulated concrete walls. Building and Environment, 2004, 39, 537-545.

Istat (Italian Statistic Board). $5^{\circ}$ Censimento dell'agricoltura. Istat, 2000, Rome, Italy.

Italian Republic. Republic President Decree 6 June 2001, nr. 380. Testo unico delle disposizioni legislative e regolamentari in materia edilizia. (Consolidated act of law and regulation provisions in building matter). Official Gazette 245, Ordinary Supplement 239, 2001, Rome, Italy.

Italian Republic. Legislative Decree 3 April 2006, nr. 152. Norme in materia ambientale. (Environmental code). Official Gazette 88, Ordinary Supplement 96, 2006 , Rome, Italy.

Italian Republic. Legislative Decree 6 November 2007, nr.
193. Attuazione della direttiva 2004/41/CE relativa ai controlli in materia di sicurezza alimentare e applicazione dei regolamenti comunitari nel medesimo settore (Fulfilment of EC directive 2004/41 about food safety controls and pursuance of EC regulation in the same field). Official Gazette 261, Ordinary Supplement 228, 2007, Rome, Italy.

Italian Republic. Legislative Decree 16 January 2008, nr. 4. Ulteriori disposizioni correttive ed integrative del decreto legislativo 3-4-2006, n. 152, recante norme in materia ambientale. (Further corrective and integrative instructions of legislative decree 3-4-2006 nr. 152, regarding environmental code). Official Gazette 24, Ordinary Supplement 24, 2008a, Rome, Italy.

Italian Republic. Legislative Decree 9 April 2008, nr. 81. Attuazione dell'articolo 1 della legge 3-8-2007, n. 123, in materia di tutela della salute e della sicurezza nei luoghi di lavoro. (Fulfilment of article 1 of law 3-8-2007, nr. 123, about health protection and safety in workplaces). Official Gazette 101, Ordinary Supplement 108, 2008b, Rome, Italy.

Jacquet P., Capdeville C. Installazioni vinicole. (Winery facilities). Eno-one, 2007, Reggio Emilia, Italy.

Tassinari P. Analisi evolutive del sistema insediativo rurale: approfondimenti metodologici e primi risultati. (Evolutionary analyses of the rural settlement system: methodological insights and first results). Architettura del Paesaggio, 2007, 16, 1-19.

Tassinari P., Carfagna E., Benni S., Torreggiani, D. Widearea spatial analysis: A first methodological contribution for the study of changes in the rural built environment. Biosystems Engineering, 2008, 100 (3), 435-447.

van der Voordt D.J.M., van Wegen H.B.R. Architecture in Use: An Introduction to the Programming, Design and Evaluation of Buildings. Architectural Press, 2005, Oxford, England.

\section{SUMMARY}

The study represents the first step of a broader research aimed at outlining specific building and landscape design criteria for small to medium-sized farm wineries. With reference to a study area of the EmiliaRomagna region (Italy) representative of the regional wine-growing and producing sector, the specific aims of the study are the identification and quantification of the main production parameters, and the formulation of a preliminary framework of dimensional and functional requirements of wineries. We acquired, georeferenced, and analysed the available databases about wine farm production and sizes. We analysed a representative sample of such farms and the national and local codes about building design for that sector. The study has led to the definition of the main characters of the production process and a layout of the main parameters influencing the design process.

Keywords: farm wineries, functional needs, building design. 
004_Tassinari(593)_25 15-09-2011 12:21 Pagina 32 